Edición Extraordinaria. p.p. $286-294$

Memorias del VIII Encuentro Nacional de Experiencias en Enseñanza de la Biología y la Educación Ambiental. III Congreso Nacional de Investigación en Enseñanza de la Biología.

\title{
PERSPECTIVA DE NIÑOS Y NIÑAS DE TRANSICIÓN SOBRE NATURALEZA ${ }^{1}$
}

\section{RESUMEN}

Se exploró la perspectiva de niños y niñas de transición sobre naturaleza. Más específicamente se indagó cómo definen la naturaleza y el medio ambiente y qué sentimientos les genera. Participaron 49 niños y niñas entre los cinco y siete años de edad de dos instituciones de educación formal en el contexto urbano y se usaron diversas herramientas que atendieron la expresión oral, escrita y gráfica. Los resultados muestran que los niños y las niñas de transición tienden a definir la naturaleza como elementos aislados, en su mayoría bióticos, que es confuso para ellos si los seres humanos hacemos parte de la naturaleza, que para ellos la naturaleza está a la vez cerca pero lejos y que medio ambiente es un concepto difícil de definir a esta edad. Manifestaron sentimientos positivos frente a la naturaleza (emoción, curiosidad, alegría), evidenciando biofilia en la primera infancia en el contexto citadino. Las herramientas que capturan la voz de los niños resultaron siendo muy informativas pues muestran una perspectiva más dinámica y compleja. Los resultados demuestran que niños y niñas de transición tienen una perspectiva clara sobre naturaleza y señalan algunos aspectos por fortalecer, en particular abordar más explícitamente la diversidad biológica y ambiental y reconocer que los humanos somos parte integral de ella y lo que esto implica.

Palabras clave: naturaleza, medio ambiente, niños y niñas, transición, percepción ambiental.

\section{PERSPECTIVES OF TRANSITION GRADE CHILDREN ABOUT NATURE}

\section{ABSTRACT}

With this project it was explored the perspective that children at kindergarten (transition) have about nature. More specifically, it was investigated how children define nature and environment and what feelings does nature generate to them. 49 boys and girls from five to seven years old participated in the study. They attended two formal education institutions in a urban context. Different research tools were C used to cover oral, written and graphic expression. Results show that kindergarten children tend to define nature as isolated elements, mostly biotic, that it is not clear for them if human beings are part of nature, that for them nature is both near and far

${ }^{1}$ Silva-Garnica, Natalia. Universidad de La Sabana, nasilvag@gmail.com 
Memorias del VIII Encuentro Nacional de Experiencias en Enseñanza de la Biología y la Educación Ambiental. III Congreso Nacional de Investigación en Enseñanza de la Biología.

away, and that environment is a concept hard to define at this age. They manifested positive feelings towards nature (excitement, curiosity, happiness), providing evidence of biophilia in early childhood at urban contexts. Research tools that incorporated the voice of children were more informative regarding their perspective as they give a more dynamic and complex view than written and graphic tools. Results effectively evidence that kindergarten children have a well formed perspective about nature and highlight points to consider for strengthening this aspect, in particular the need to study biodiversity in a more explicit way in early childhood and of recognizing ourselves as part of nature and what this implies.

Key words: nature, environment, early childhood education, children, environmental perception.

\section{INTRODUCCIÓN}

La forma de relacionarnos con el entorno está siendo tan insostenible que desde hace algunas décadas la educación ambiental se ha venido presentando como una estrategia formal y oficial para sensibilizar a los ciudadanos sobre su relación con el ambiente y darle herramientas para tomar decisiones más asertivas (Stapp et al., 1969; EPA, 2014). No obstante, pese a la cantidad de iniciativas ambientales que se han adelantado, poco énfasis se ha hecho en conocer las perspectivas que tienen los niños y las niñas sobre medio ambiente y naturaleza, y mucho menos han sido tenidas en cuenta a la hora de desarrollar iniciativas de educación ambiental.

Algunos autores señalan que desconocer la mirada y las necesidades de los niños puede resultar en actividades muy abstractas para ellos, llegando incluso a confundirlos y a desconectarlos de su entrono natural (Phenice \& Griffore, 2003; White, 2004). Por otro lado, reconociendo que "la percepción determina juicios, decisiones y conductas, y conduce a acciones con consecuencias reales". (Pidgeon, 1998; citado en Flores \& Herrera, 2012), conocer las percepciones posibilita llegar a causas primarias de comportamientos y actitudes frente al entorno y promover un mejor direccionamiento.

Investigaciones sobre la perspectiva de los niños y las niñas sobre naturaleza y medio ambiente se han realizado al menos en Canadá (Burgess \& Mayer-Smith, 2011), Australia (Keliher, 1994; Loughland et al., 2003), Inglaterra y México (Barraza, 1999; 2001; 2003). Estos han tendido a utilizar una o pocas herramientas de recolección de información y se han orientado principalmente a niños mayores de ocho años. En el contexto latinoamericano hay muchos vacíos al respecto, por lo que el presente estudio constituye un paso valioso para la región. 
Memorias del VIII Encuentro Nacional de Experiencias en Enseñanza de la Biología y la Educación Ambiental. III Congreso Nacional de Investigación en Enseñanza de la Biología.

El objetivo general de esta investigación fue indagar la mirada sobre naturaleza que tienen niños y niñas que cursan transición a través de diferentes herramientas, con el fin de orientar estrategias pedagógicas que fortalezcan su conexión con el mundo natural (Silva-Garnica, 2014). Específicamente se buscó 1) Identificar qué concepto tienen sobre el término naturaleza, 2) contrastar esta perspectiva con la que tienen sobre medio ambiente, 3) evidenciar qué sentimientos les genera la naturaleza ,4) evidenciar si los niños y las niñas de transición reconocen la existencia de problemáticas ambientales y qué postura tienen ante ellas, 5) determinar las principales fuentes de aprendizaje sobre naturaleza, y 6) identificar herramientas pertinentes para indagar la perspectiva de niños y niñas de entre cinco y siete años de edad. En el presente artículo sólo se presentan los resultados para los objetivos específicos uno, dos y tres.

\section{METODOLOGÍA}

Este fue un estudio de tipo fenomenológico, con un enfoque mixto y un alcance exploratorio-descriptivo. Se realizó en dos instituciones de educación formal de la ciudad de Bogotá: una es un colegio bilingüe, femenino, confesional, calendario $B, y$ orientado a atender una población de estrato socioeconómico alto, y la otra es un centro educativo no bilingüe, mixto, calendario $A, y$ orientado a atender una población de estrato socioeconómico bajo. En el colegio se trabajó con 17 niñas y en el centro con 32 niños y niñas, todos entre los cinco y siete años de edad. Las herramientas de recolección de información hicieron parte de actividades pedagógicas y en algunos casos se aplicaron en los descansos.

Se emplearon diversas herramientas con el fin de triangular la información, de ofrecer diferentes medios de expresión a los participantes, y de validar las herramientas mismas. Las herramientas consistieron en dibujos sobre naturaleza y medio ambiente acompañados de su explicación oral, un cuestionario de selección múltiple con el que se exploraron conceptos y sentimientos frente a la naturaleza, una encuesta basada en imágenes en donde debían completar la frase "en este dibujo veo...", y una entrevista con una serie de preguntas orientadas a indagar conocimientos y sentimientos sobre naturaleza, medio ambiente y problemáticas ambientales. Se realizaron análisis de contenido con los que se definieron categorías, y a partir de estas se realizaron histogramas de frecuencia. Para la aplicación de los instrumentos se contó con el consentimiento informado de los directivos de la institución educativa, así como con el de los niños y las niñas participantes.

\section{RESULTADOS Y DISCUCIÓN}


Memorias del VIII Encuentro Nacional de Experiencias en Enseñanza de la Biología y la Educación Ambiental. III Congreso Nacional de Investigación en Enseñanza de la Biología.

Frente al concepto que los niños y niñas puedan tener sobre naturaleza se identificaron cinco categorías: Elementos (listado de elementos discretos, como "una jirafa, las mariposas y el sol y el árbol"), Categorías (grupos de elementos, como "peces, animales, árboles"), Ecosistemas ("bosque", "desierto"), Cualidades ("amor", "música", "peces felices"), y Situaciones ("un mono trepándose en el árbol para cazar las bananas").

Todos los participantes conciben la naturaleza como una serie elementos aislados siendo frecuente encontrar la combinación pasto, árboles, flores y sol. Esto concuerda con resultados de investigaciones anteriores para niños de seis años (Keliher, 1997) y mayores (Loughland, et al. 2002; Barraza \& Ceja-Adame, 2003). No obstante, la respuesta no es uniforme. Las diferentes herramientas evidencian que hay niños que la asocian también a categorías, como plantas y animales, lo cual hace referencia a un proceso cognoscitivo diferente al de listar elementos. Algunos pocos se refirieron a ecosistemas particulares (bosque, pradera) lo cual no es de extrañar pues a esta edad los ecosistemas como tal no han sido introducidos formalmente en la escuela y no son tan tenidos en cuenta en el contexto urbano en el que se desenvuelven, en cuyo caso toma mayor relevancia la influencia del contexto familiar. Otros cuantos participantes en su mayoría niñas - se refirieron a la naturaleza como cualidades, específicamente como amor, y algunos la definieron como situaciones particulares, relacionadas principalmente con el cuidado y con dinámicas ecológicas. Por su parte, un niño del centro la asoció directamente con un municipio (Tocancipá), señalando la importancia de las experiencias personales y de la dimensión socioafectiva en la formación de conceptos a temprana edad. Esta participación sugiere una nueva categoría de análisis: Lugar. Estos resultados demuestran que efectivamente los niños desde temprana edad construyen representaciones mentales del mundo que los rodea (Oaters \& Andrew, 2004) y que existen diferentes procesos de estructuración mental para un mismo rango de edad. Además, las entrevistas y explicaciones orales evidenciaron perspectivas menos estáticas y aisladas de las que los dibujos muestran por sí mismos, demostrando la importancia de escuchar la voz de los niños y las niñas en este tipo de estudios.

En cuanto a los elementos mencionados, los elementos bióticos tienen el protagonismo (figura 1). Las plantas tienden a ser nombradas más frecuentemente que los animales aunque rara vez se nombran especies particulares. Se trata básicamente de elementos generales y cercanos a su contexto, como "árboles", "pasto" y "flores". Del cuestionario surge que su planta favorita en más del $90 \%$ de los casos es una flor, y con gran ventaja es la rosa. En vista de la gran variedad de plantas y de flores que existen - en especial en nuestro país - valdría la pena trabajar de forma más explícita este tema con los niños y las niñas. Podrían al menos acercarse más a las plantas que hay en el colegio y en los lugares donde viven. 
Memorias del VIII Encuentro Nacional de Experiencias en Enseñanza de la Biología y la Educación Ambiental. III Congreso Nacional de Investigación en Enseñanza de la Biología.

Figura 1. Elementos generales representados en los dibujos sobre naturaleza. El porcentaje es relativo al tamaño de la muestra (total=47, colegio=17, centro=30. Total equivale a la suma de ambos grupos con el fin de evidenciar las tendencias generales).

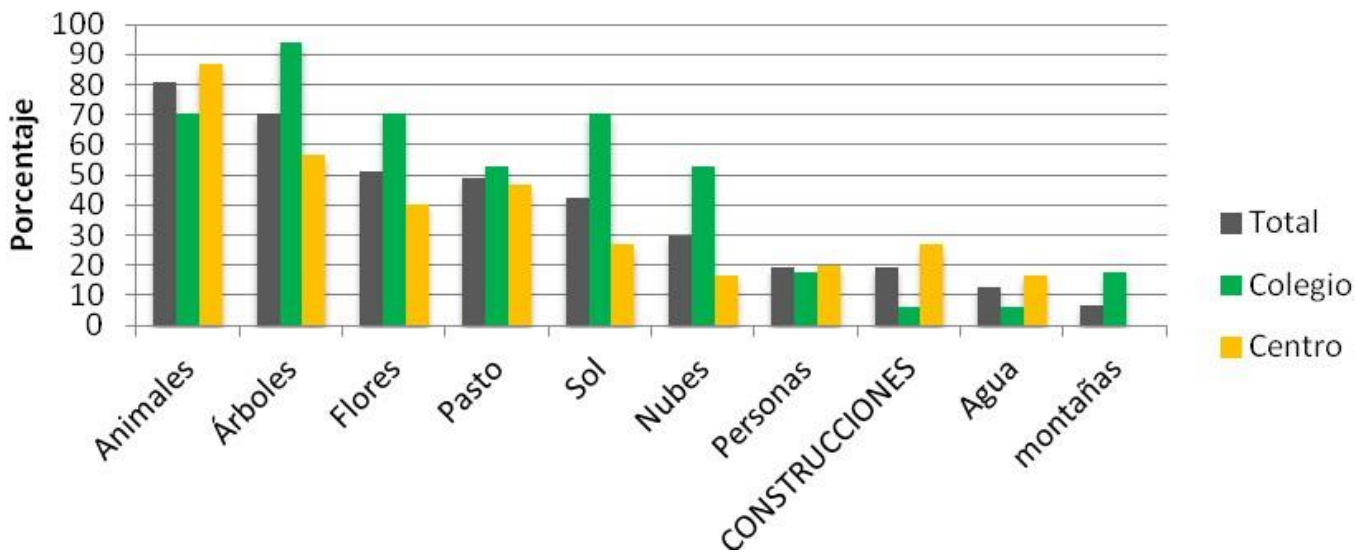

Entre los animales mencionaron más comúnmente a los mamíferos, especialmente a las mascotas y a los grandes mamíferos africanos. También fueron muy nombradas las mariposas, sobre todo por las niñas. Solo en un par de casos dibujaron peces y en otro par reptiles. Aquí igualmente valdría la pena explorar más los animales presentes en su colegio y en su barrio como punto de partida para reconocer la gran diversidad de formas de vida que nos rodea. Esto no solo generaría mayor sensibilidad ambiental, sino mayor identidad y probablemente un mayor interés por la conservación y el desarrollo sustentable. Paralelamente, es también importante enfatizar que hay otras formas de vida además de las plantas y animales, como lo son los hongos y las bacterias, pues pocos niños mencionaron los hongos presentes en las imágenes trabajadas y ninguno los incluyó en sus dibujos.

Por otro lado, el $57 \%$ de los niños y niñas incluyeron elementos abióticos en sus dibujos, los cuales consistieron en el sol, las nubes, las montañas, el arcoíris (1 caso) y cuerpos de agua. Poco los nombraron al preguntarles por los elementos de la naturaleza presentes en su lugar de vivienda (un par de niños nombraron el aire y el agua). Las entrevistas revelaron que para algunos no es claro si las piedras son o no naturaleza "porque no crecen", - si las nubes lo son "porque están en el cielo". Nuevamente resulta relevante abordar los elementos abióticos más explícitamente con los niños y las niñas para generar consciencia de las dinámicas ecológicas y sensibilización sobre la forma como estamos relacionados con entorno.

De forma paralela, la mayoría de niños y niñas considera que la naturaleza está cerca (figura 2) pero algunos sugieren que para estar más conectados con ella hay que "ir a ella". Esto evidencia la paradoja que encontró Keliher (1997) de que la naturaleza "está 
Memorias del VIII Encuentro Nacional de Experiencias en Enseñanza de la Biología y la Educación Ambiental. III Congreso Nacional de Investigación en Enseñanza de la Biología.

cerca pero a la vez lejos". Así mismo, varios se mostraron confundidos sobre si el ser humano hace parte de la naturaleza (figura 2) y plantearon diversas hipótesis sobre el por qué podrían ser así, como que es una elección que uno hace, que sucede porque uno toma agua como las plantas o se da porque uno cuida a la naturaleza. Sin duda el punto del rol del ser humano en la naturaleza requiere ser atendido con más énfasis en la educación inicial.

Figura 2. Respuesta de los niños y las niñas frente a las preguntas ¿me gusta la naturaleza?, ¿la naturaleza está cerca?, ¿yo hago parte de la naturaleza?, y ¿donde vivo hay naturaleza? ( $n$ colegio=17, $n$ centro=30 n).

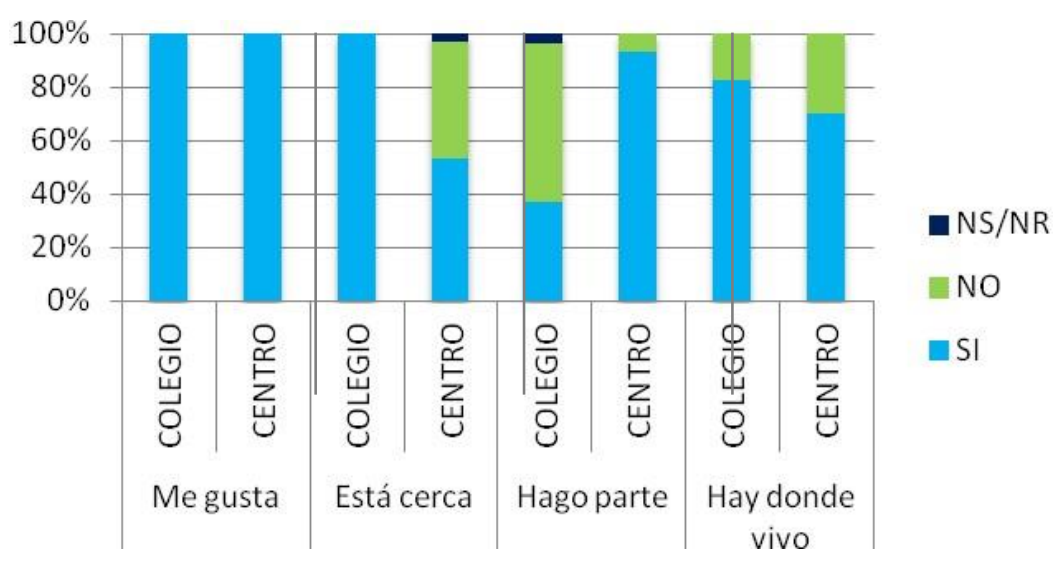

En cuanto a la dimensión afectiva, los niños y las niñas citadinos manifestaron sentir emoción, alegría y curiosidad frente a la naturaleza (figura 3), demostrando que en ellos está mucho más desarrollada una cercanía (biofilia) que una separación (biofobia) hacia esta (Phenice \& Griffore, 2003; White, 2004). Sin embargo, algunos confiesan que a veces sienten miedo, y comentan que hay animales que pueden hacer mucho daño. Otros, por su parte, manifiestan que les da rabia y tristeza la forma como los humanos tratamos la naturaleza. Este aspecto emocional no se había explorado anteriormente en estudios de percepción ambiental, y demuestra que los niños no perciben el entorno de forma neutral sino que sus emociones están muy involucradas. Vale la pena mencionar que hablar de lo que sienten no siempre es fácil para los niños; en varias ocasiones decían no saber, respondían diciendo más lo que pensaban que lo que sentían o se enfocaban en sensaciones más que en sentimientos (como "siento que estoy ahi" o "siento que estoy volando"). 
Memorias del VIII Encuentro Nacional de Experiencias en Enseñanza de la Biología y la Educación Ambiental. III Congreso Nacional de Investigación en Enseñanza de la Biología.

Figura 3. Sentimientos que la naturaleza genera en niños y niñas del centro y del colegio ( $n$ colegio=17, $n$ centro=30).

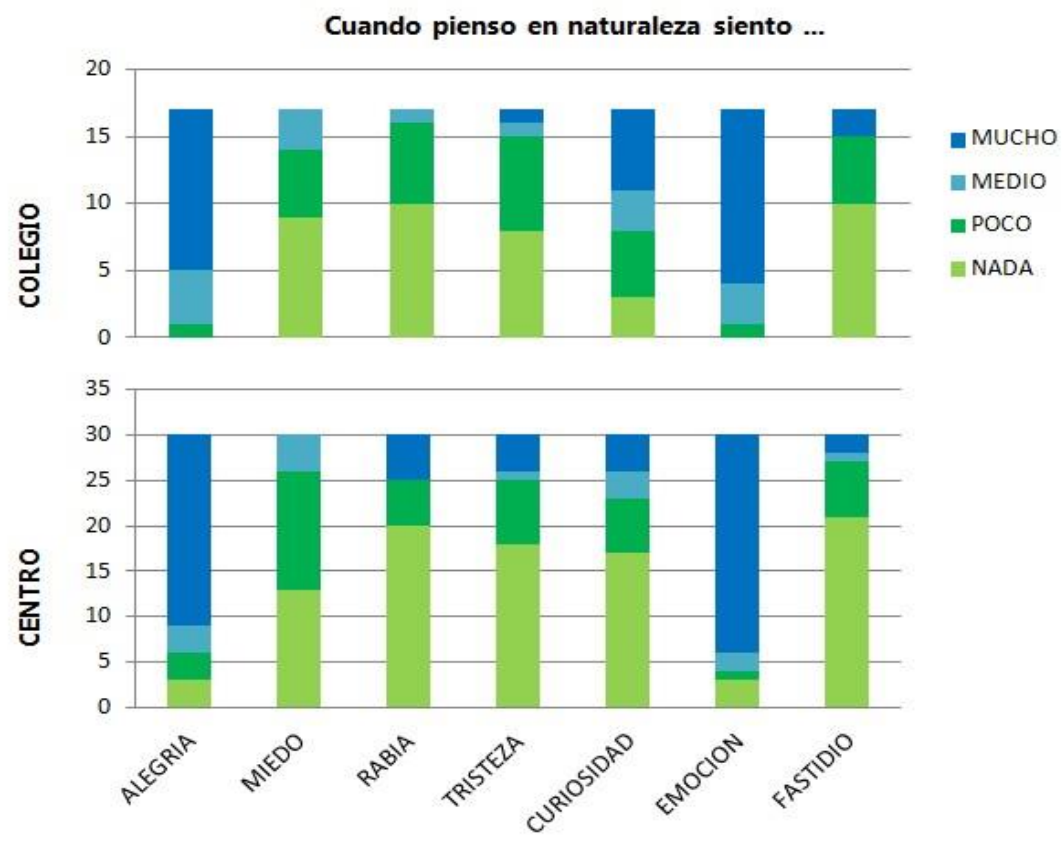

Al explorar la perspectiva frente al medio ambiente se encontró confusión en los niños y las niñas, en especial en los del centro. La mayoría dijo no haber escuchado el término y dibujó algo similar a lo dibujado para la naturaleza. Las niñas del colegio tendieron a relacionarlo con factores climáticos (llueve vs. hace sol) y con arrojar o no basura en el parque. Algunos además incluyeron elementos como carros o edificaciones, e incluso una niña del colegio dibujó una cárcel con personas adentro. Esto evidencia, por un lado, que no necesariamente para los niños y las niñas medio ambiente es sinónimo de naturaleza; y por otro, que lo asocian más a factores abióticos y a condiciones de estos elementos. Adicionalmente, incluyen en él al hombre más claramente que en el concepto de naturaleza, por medio de sus acciones (botar o no basura al piso) o de sus construcciones (carros y edificaciones).

Finalmente, las herramientas empleados fueron efectivas y pertinentes para capturar la perspectiva de los niños y las niñas, y especialmente brindaron una mirada más completa al abarcar diferentes medios de expresión. Los métodos gráficos, usados previamente en estudios sobre perspectivas de naturaleza (Barraza, 1999; Barraza y Ceja-Adame, 2003; Villuendas et al. 2005), resultaron siendo insuficientes por sí mismos aunque pueden constituir una buena herramienta de exploración inicial. En los dibujos los niños plasman situaciones concretas y específicas a costa de una mirada profunda de su perspectiva. El cuestionario adaptado a la edad resulta ser más efectivo que el dibujo si lo que se trata es de capturar mayor información en poco tiempo y de generar análisis 
Memorias del VIII Encuentro Nacional de Experiencias en Enseñanza de la Biología y la Educación Ambiental. III Congreso Nacional de Investigación en Enseñanza de la Biología.

más sistemáticos. Por su parte, las habilidades escritas sí parecen limitar las respuestas que los niños y niñas puedan dar, por lo que entre más cerradas y concretas sean las preguntas es mucho mejor. No obstante, las entrevistas son sin duda la herramienta que más deja ver la perspectiva de los niños y las niñas, no solo porque permite profundizar las respuestas sino porque le da una calidad diferente a las mismas, evidenciando más acciones y cualidades que los medios gráficos y escritos. Además, las discusiones grupales resultaron ser muy motivantes para los participantes y muy enriquecedoras, por lo que se sugiere tenerlas más en cuenta en estudios similares.

La triangulación de los resultados muestra que no en todos los casos las respuestas fueron consistentes, especialmente para el concepto de medio ambiente, lo que puede estar evidenciando dudas internas o falta de claridad frente a los conceptos. Sin embargo, algunos participantes sí fueron muy consistentes, demostrando que a esta edad sí se pueden tener opiniones claras sobre un tema, y eso tal vez está mediado por el acompañamiento o la experiencia en casa.

\section{CONCLUSIONES}

Este estudio evidencia que los niños y las niñas de transición tienden a definir la naturaleza como elementos aislados, en su mayoría bióticos, pudiendo en algunos casos definirla como categorías, situaciones, cualidades, ecosistemas y lugares geográficos. No obstante, esta perspectiva más profunda y dinámica sólo se evidencia cuando se registra su voz y cuando se usan diversas herramientas complementarias. El concepto de medio ambiente es confuso a esta edad, así como la relación entre el ser humano y la naturaleza. Los sentimientos que genera la naturaleza son principalmente emoción, curiosidad y alegría, evidenciando biofilia en la primera infancia en el contexto citadino. En general, los resultados señalan la necesidad de abordar más la biodiversidad desde la primera infancia, haciendo hincapié en las especies de su contexto físico y de su país así como en el inherente dinamismo $e$ interdependencia que caracteriza al mundo natural. También se hace necesario abordar más explícitamente los elementos abióticos y comprender cómo los seres vivos nos relacionamos cotidianamente con ellos.

\section{BIBLIOGRAFÍA}

Barraza, L. (1999). Children's drawings about the environment. Environmental Education Research, 5 (1), 49-66

(2000). Educar para el futuro: En busca de un nuevo enfoque de investigación en Educación ambiental. En: Memorias Foro Nacional de Educación Ambiental. UAA, SEP y SEMARNAP. P. 253-260 
Memorias del VIII Encuentro Nacional de Experiencias en Enseñanza de la Biología y la Educación Ambiental. III Congreso Nacional de Investigación en Enseñanza de la Biología.

(2001). Perceptions of social and environmental problems by English and Mexican school children, Canadian Journal of Environmental Education, 6, 139157.

L y Ceja-Adame, M.P. (2003) 16. Los niños de la comunidad: su conocimiento ambiental y su percepcion sobre "naturaleza". En: Velásquez, Torres y Bocc. Las enseñanzas de San Juan. Investigación participativa para el manejo integral de recursos naturales. México: Instituto Nacional de Ecología.

Burgess, D.J. y Mayer-Smith, J. (2011) Listening to Children: Perceptions of Nature. The Journal of Natural History Education and Experience (5): 27-43.

Keliher, V. (1997) Children's perception of nature. International Research in Geographical and Environmental Education, 6(3): 240-243

Loughland, T.; Reid, A.; Walker, K. y Petocz, P. (2002). Young people's conceptions of environment: a phenomenological analysis. Environmental Education Research, 8 (2): 187-197

(2003) Factors influencing youn people's conception of environment. Environmental Education Research, 9 (1): 3-19

EPA. (2014) What is Environmental Education?. http://www2.epa.gov/education/whatenvironmental-education

Flores, R.C. \& Herrera, L. (2010). Estudio sobre las percepciones y la educación ambiental. Tiempo de educar, 11(22): 227-249

Oaters, J. \& Andrew, G. (2004). Cognitive and Language Development in Children. Blackwell Publishing: Oxford. Pags 346

Phenice, L. \& Griffore, J.R. (2003). Young children and the natural World. Contemporary Issues in Early Childhood, 4(2), 167-171. Recuperado el 29 de abril de 2014, en http://dx.doi.org/10.2304/ciec.2003.4.2.6

Silva-Garnica, N. (2014). Perspectiva de niños y niñas de transición sobre naturaleza. Universidad de La Sabana, Chía, Colombia. Disponible en: http://intellectum.unisabana.edu.co/handle/10818/12996

Stapp, W. B. et al. (1969) The Concept of Environmental Education. Journal of the Environmental Education 1(1): 30-31. Disponible en: http://www.hiddencorner.us/html/PDFs/The Concept of EE.pdf

Villuendas, M.D., Liébana, J.A., Fernández, R. \& Córdoba, F. (2005). Representaciones ecológicas en la infancia y estilos de vida. Educar 36: 13-30

White, R. (2004) Young Children's Relationship with Nature: Its Importance to Children's Development \& the Earth's Future. White Hutchinson Leisure \& Learning Group [en línea]. Recuperado el 8 de abril de 2013 de: http://www.whitehutchinson.com/children/articles/childrennature.shtml 